\title{
Security and Watering System Counseling Based on Internet of Things (IoT) in Pondok Hijau Indah Residential Area
}

\section{LITA LIDYAWATI, LUCIA JAMBOLA, ARSYAD RAMADHAN DARLIS, LISA KRISTIANA, RATNA SUSANA}

\author{
Institut Teknologi Nasional Bandung \\ Email: lita@itenas.ac.id
}

Received 25 October 2020 | Revised 13 November 2020 | Accepted 29 November 2020

\begin{abstract}
Nowadays, security and gardening systems in densely populated residential areas are generally done manually. The security system in housing sometimes places security posts at street corners that are some distance from citizen's homes thus they cannot be monitored at all times. Whereas other problem of watering system in citizen's homes, someone has to water the plants one by one that it is not efficient in energy, time and water availability thus that it can reduce the quality of the plants. Internet of Things (IOT) is a concept and method for remote control, monitoring, and various tasks. IoT is connected to a network that it can be accessed anywhere which can make things easier. IoT can be used to solve various problems. One of them is security issues and gardening activities. By using smart home technology, the security system is carried out by placing CCTV (Closed Circuit Television) which can be accessed by the home owner, anytime and anywhere the home owner is located. On the other hand, gardening is one of the most popular hobbies. In this field, IoT can be used to monitor and regulate various things to support gardening activities. In this community service activity, we are proposed a simple automatic gardening system for watering some plants programmatically in Pondok Hijau Indah residence. The system also allows manual human intervention either locally or remotely via the internet to control CCTV and water pumps. To build this smart Home system we will use the Xiaomi Home application from Google Play. In this application, we can set a program to control CCTV and water the plants every day at a certain time periodically, in this case, we set every 7 hours to watering the plants.
\end{abstract}

Keywords: IoT, CCTV, google play, Xiaomi, smart home

\section{INTRODUCTION}

The development of information technology has had an impact on globalization, the demands of work and the demands of a lifestyle are increasing. The use of IoT is a 
development to generate new business opportunities by connecting physical objects with many sensors (Sugiono, 2017).

Internet of Things (IoT) is where every day physical objects connected to the internet in one form of monitoring and control or another in real time. The Internet of Things (IoT) model in smart home control which functions to control several electronic devices in the home such as controlling CCTV (Closed Circuit Television), turning on lights, fans, air conditioners, water pumps, and others.

The proposed IoT method is inspired by the problems faced by the community where they find it difficult to monitor their homes and regulate watering of garden plants when they are traveling far and do not return home for a long time. In this case, we provide a counseling to several residents and try to apply the IoT method in one of the residents' houses in Pondok Hijau Indah residence, where there are many problems regarding security and irrigation for plants in the yard because the owner does not live in the house.

In general, many people install CCTV cameras at home to monitor the house when it is empty. However, there is no direct notification to the home owner when an unwanted person is detected by the CCTV camera system. Closed Circuit Television (CCTV) surveillance remains a growing industry in response to increased security threats, and whilst new developments have brought clearer images, digital recording and high-speed data transmission, effective security systems (Cieszynski, 2001). IoT developers and researchers are actively involved to uplift the life style of the disabled and senior age group people. IoT has shown a drastic performance in this area and has provided a new direction for the normal life of such people (Sachin, 2019).

Meanwhile, watering is an effort to provide and regulate water to support agriculture and plantations. On a small scale, watering can be applied to garden in the yard of the house and this also requires the provision and management of water thus that plants can be irrigated on a scheduled basis. Traditional irrigation methods are less able to perform proper and fast water drainage. On the other hand, if the owner is not at home, the plants in the garden will experience drought.

To solve this problem, we need a new and automatic method to create irrigation that can be controlled remotely and automatically. By utilizing mobile phones, especially in internet facilities, the application of the internet as a means for remote control will be integrated with several smart tools. This system will have access to control CCTV and provide reports if it detects a movement and opens and closes the irrigation channel portal that has been created and how to control the system remotely via the internet network which is now called the Internet of Things (IoT) while it can make easier for the community to irrigate the plants even if they are far from the house.

Surveillance systems are an essential part of securing your home. These systems can range from wireless home security cameras to sophisticated alarm systems that notify law enforcement at the first sign of trouble. The presence of security cameras can serve as a deterrent to would-be thieves, while hidden cameras can protect discretely. An oftenoverlooked aspect of an alarm system is the recording device. After all, notifying law enforcement and sounding an intimidating siren from your alarm system is only half a solution. A Digital Video Recorder (DVR) or a Network Video Recorder (NVR) system provides evidence of whatever set off the alarm in the first place. If you have the extra bandwidth on your network, the higher quality video and easier setup of NVR is likely the best choice. 
Design and implementation of security for smart home based on GSM technology was discussed by Govinda et. al. that provides two methods to implement home security using IoT (Govinda, 2014). One is using web cameras such that whenever there is any motion detected by the camera, it sounds an alarm and sends a mail to the owner. This method of detecting intrusion is quite good, albeit somewhat expensive due to the cost of the cameras involved in the process. The cameras need to be of good quality which means it should have a wide range and the picture quality should be high enough to detect movement.

SMS based system using GSM was proposed by Karri and Daniel propose to use internet services to send messages or alert to the house owner instead of the conventional SMS (Karri, 2005). Jayashri and Arvind have implemented a fingerprint-based authentication system to unlock a door (Jayashri, 2013). This system helps users by only allowing the users whose fingerprint are authorized by the owner of the house. This system can also be used to monitor who all have used the sender who gained entry into the house. The system is coupled with a few more home protection features such as gas leakage and fire accidents. Although a good system, fingerprint sensors are expensive and complex (as they need increased sensor resolution) to integrate into an IoT setup. Some experts also argue that only relying on a fingerprint sensor is not wise as it is relatively easy to lift someone's fingerprints and replicate them, which is why it is always advised to use fingerprint scanners in a two factor authentication systems where an additional layer of security is available in the form of PIN, passcode, voice recognition, etc.

Some researchers proposed an idea of robust IoT home security system where a fault in of one component in the system does not lead to the failure of the whole system (Cristian, 2016). The idea of using multiple devices which may or may not be directly compatible with each other but can be made to work in such a way that they can replace an existing component of the system in case of a fault. In tandem to this, the models have the ability to use overlap between various devices which would result in preserving energy thus making the model more efficient.

The scope of problems of this activity is provision of knowledge to the community about IoT application for home security and gardening irrigation. After participating in this activity, the community optimally can use and understand the Internet of Things for many fields.

\section{METHODS}

The initial stage of this activity is the introduction of the concept of the internet of things (IoT), followed by examples and case studies application of the current IoT. Afterwards, we explained an overview of future IoT development with discuss the challenges and risks of using IoT. Then, explain the advantages and benefits of IoT for personal productivity, in this case is for a home security and gardening irrigation. Finally, we implemented the hardware of the security and gardening irrigation system in Pondok Hijau Indah Residential.

\subsection{Introduction of Internet of Things Concept}

Describe the concept of the Internet of Things (IoT) as technology that changes lifestyle. IoT is no longer a new technology but a modern concept which began to change people's lifestyle.

The Internet of things (IoT) describes the network of physical objects that are embedded with sensors, software, and other technologies for the purpose of connecting and exchanging data with other devices and systems over the Internet. 
The definition of the Internet of things has evolved due to the convergence of multiple technologies, real-time analytics, machine learning, commodity sensors, and embedded systems. Traditional fields of embedded systems, wireless sensor networks, control systems, automation (including home and building automation), and others all contribute to enabling the Internet of things. In the consumer market, IoT technology is most synonymous with products pertaining to the concept of the "smart home", including devices and appliances (such as lighting fixtures, thermostats, home security systems and cameras, and other home appliances) that support one or more common ecosystems, and can be controlled via devices associated with that ecosystem, such as smartphones and smart speakers. There are a number of serious concerns about dangers in the growth of IoT, especially in the areas of privacy and security, and consequently industry and governmental moves to address these concerns have begun including the development of international standards.

\subsection{Examples and Case Studies Of IoT}

Nowadays, the use of the Internet of Things (IoT) has been widely applied in various fields such as health, industrial, urban and even agricultural. The concept of IoT itself very much needed, especially in Gardening and Security area. People who live in cities tend to have space constraints not wide enough and also a limited time to maintain plants for gardening. Meanwhile, the security in urban area will be an issue that must be considered.

By applying the IoT technology on the urban gardening will certainly be make it easier for people living in urban areas to monitor existing plants. IoT based drip irrigation system give complete control over the plants from monitoring plant conditions in real time and to control use of water discharge. This system is is suitable the home owner to control and monitor the plants via smartphone anytime and anywhere. Figure 1 shows the installation of watering system.

Home safety remains a critical issues not only in metropolitan city but sub-urban area, particularly for people who spend many activity outside home. A proven strategies to improve and make sure security system and monitoring house environment remotely is needed. In this community service activity implement the IoT connected to CCTV thus the owner can monitor the condition of the house and control the output of lights remotely using an application on the smartphone through internet connection. Figure 2. show the placement a CCTV in outside part of the house.

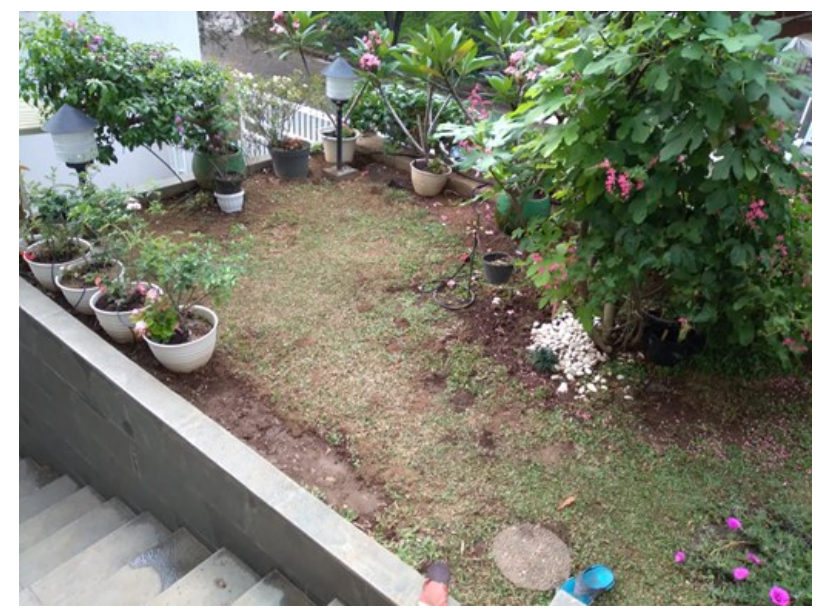

Figure 1. Watering System Installation 


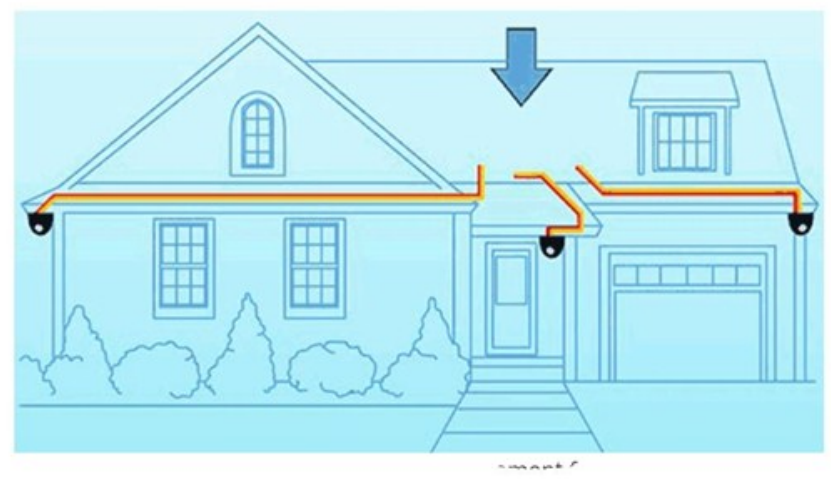

Figure 2. Front View of Typical Camera Placement for a House

\subsection{An Overview of IoT Development in The Future}

IoT is progressively becoming an important aspect of our life that can be sensed everywhere around us. In whole, IoT is an innovation that puts together extensive variety of smart systems, frameworks and intelligent devices and sensors. Moreover, it takes advantage of quantum and nanotechnology in terms of storage, sensing and processing speed which were not conceivable beforehand. Extensive research studies have been done and available in terms of scientific articles, press reports both on internet and in the term of printed materials to illustrate the potential effectiveness and applicability of IoT transformations. It could be utilized as a preparatory work before making novel innovative business plans while considering the security, assuranced interoperability. Figure 3 shows the architecture of IoT.

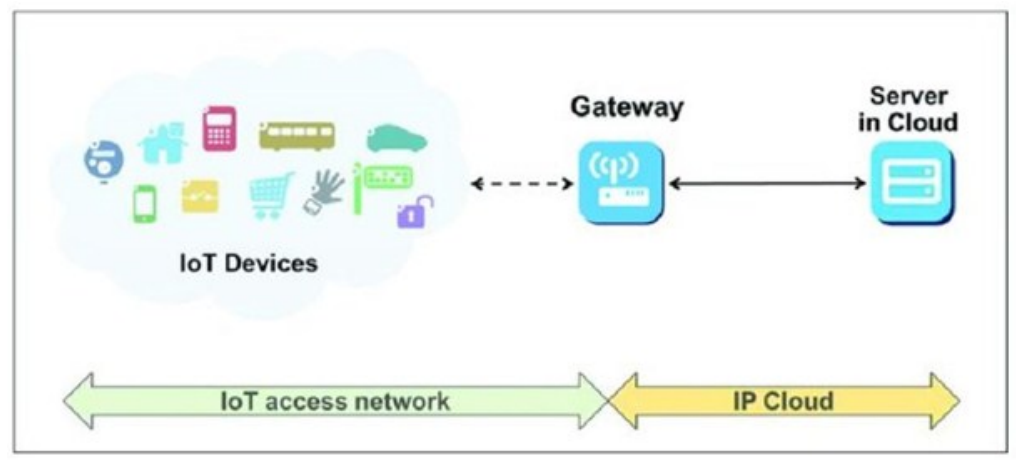

Figure 3. The Architecture of IoT (Dae-yong, 2017)

\subsection{Challenges and Risks of Using IoT}

Material on the challenges and risks of utilization IoT is given because IoT is a concept where an object has the ability to transfer data over the network without requiring humanto-human or human-to-computer interaction. This has led to the utilization of IoT security gaps that are challenges in the future such as cyber crime, identity, etc.

The Internet of Things (IoT) can increase efficiency, but it also comes with new risks. IoT security is the protection of Internet of Things devices from attack. While many business owners are aware that they need to protect computers and phones with antivirus, the security risks related to IoT devices are less well known and their protection is too often neglected. Internet of Things devices are everywhere. From cars and water pumps to monitoring devices on assembly lines, objects around us are increasingly being connected to the internet. 
While IoT devices can greatly increase productivity for business, they also come with risks. Since IoT devices are connected to the internet, they can be hacked just like any other internet-enabled device. To sufficiently protect your network, it is essential to understand the security vulnerabilities of IoT devices. One of the key IoT security issues is the expansion of attack surfaces due to an increased number of endpoints. In a network, endpoints are the devices that are connected to the internet at large-each offering a point of entry to bad actors, exposing the network to outside risks. The attack surface of a network consists of all possible places where it can be attacked, and it expands with every new internet-connected device. Even if the chance of one device being accessed by a perpetrator is small, the large number of IoT devices being brought into businesses can create a significant security risk.

\subsection{Implementation Security and Gardening Irrigation Systems}

This system is useful especially for user's who have a day job and travel a lot as this system can water plants only when necessary without any human intervention. What makes our project unique than the other innovations in the current market for watering plants is it's built in function which allows the user to be updated from time to time about the status of the system. Figure 4 shows the implementation of the watering system.

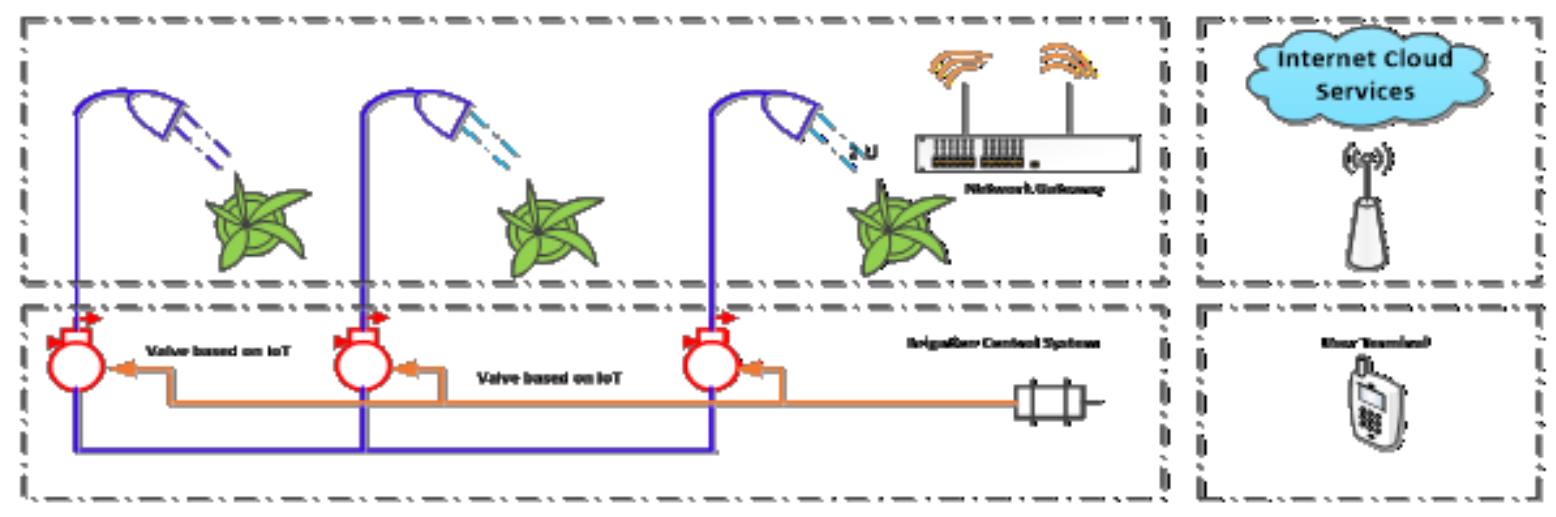

Figure 4. IoT Irrigation System Diagram (Lidyawati, 2020)

CCTV (Closed Circuit System) is a system that offers signals/footage used for the surveillance system that can protect people and property. It maintains security and privacy by not making the footage public. It is used for both small and wide area monitoring. The system has a camera, monitor, video recorder, wires and internet connection for closed-circuit monitoring.

CCTV system consists of a cameras, lenses, housing, video monitors, switchers and multiplexers, video recorders. Firstly, a need assessment is performed to finalize the location of the camera for proper security surveillance. It helps in defining the components such as angels, lighting, power distribution, etc. The camera captures the signals at the source in its digital chip. The signals are then converted into a stream of images. Depending on the location, the lens of the camera is decided such as wide angle, normal, zoom or telephoto. It focuses light onto the chip or image sensor. Inferior lens will never be able to deliver quality images. Figure 5 shows the CCTV connected to internet service via WiFi router. 


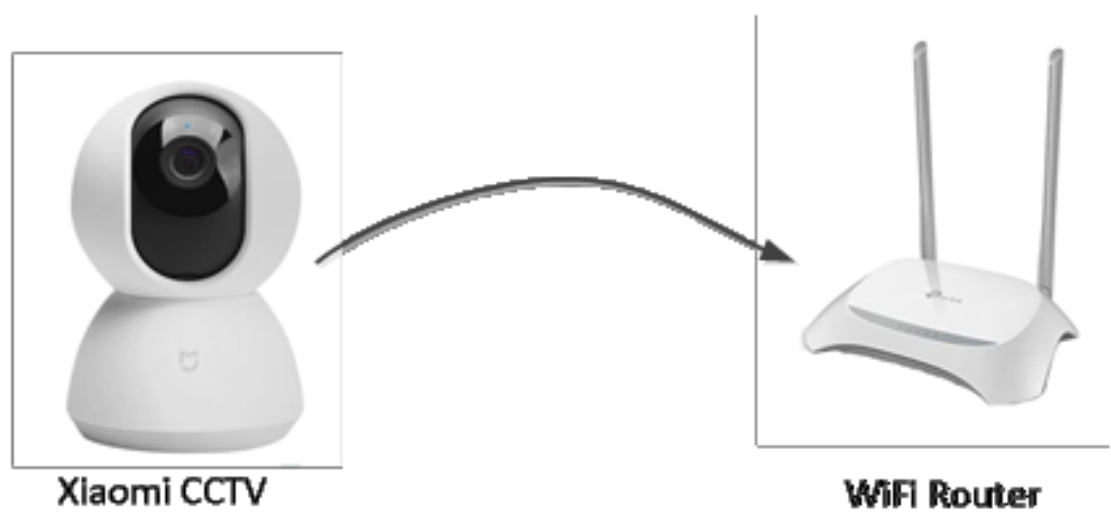

Figure 5. CCTV Installation

\section{RESULTS AND DISCUSSION}

A network camera is also commonly referred to as an IP camera. Network camera technology is similar to computer technology in that both have unique IP address. Cameras connect to a network and can work wherever a network connection is accessible. The biggest difference between a standard web camera on a computer and a network camera is that web cams require a direct connect to a computer. Network cameras can be wireless and still work through a network. Figure 6 . Shows the Xioami software to control and manage the CCTV.
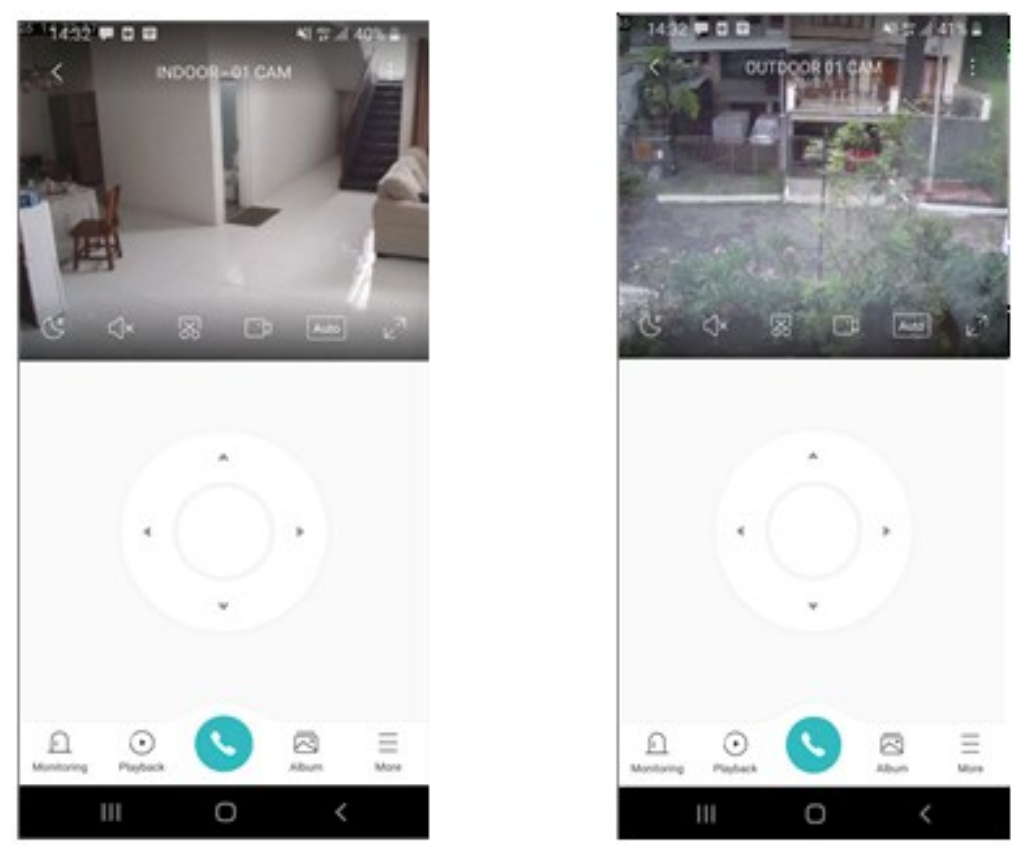

Figure 6. Xiaomi Software

If we are starting our journey in planning and installing a garden irrigation system, everything starts with effective planning. We have to map our garden, measure the property boundaries, paths, flower beds, etc. Part of this process is to understand how many outlets are required. Figure 7 shows the team was applied the drip installation. 

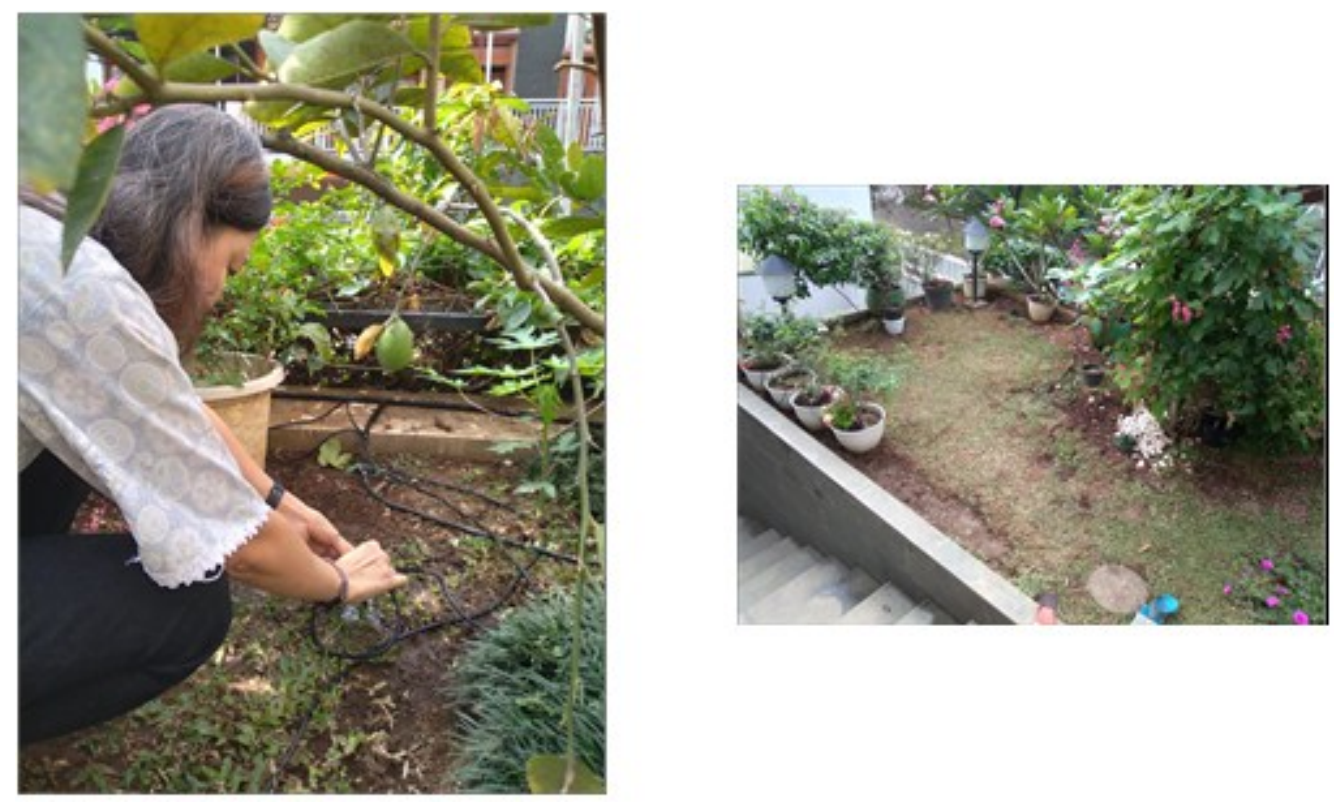

Figure 7. Drip Installation

Table 1 The Schedule of Watering System

\begin{tabular}{|c|c|c|}
\hline Schedule Period & Schedule On Time & Schedule Off Time \\
\hline Daily & 09.00 & 06.20 \\
\hline Daily & 16.00 & 16.20 \\
\hline
\end{tabular}

According to table 1 , the watering system sets the time periodically. In this case, the pumps will switch on each 6 hours during 20 minutes durations.

\section{CONCLUSIONS}

This activity provides awareness for the people about the role of using smartphones as application of the IoT. With this activity, achievements have been made goal of sustainable development to ensure the quality of education in IoT application. The watering system will turn on each 6 hours during 20 minutes durations.

\section{ACKNOWLEDGEMENT}

This study was supported by RW 16 Pondok Hijau Indah Residence. 
Security and Watering System Counseling Based On Internet Of Things In Pondok Hijau Indah Residential Area

\section{LIST OF REFERENCES}

Cieszynski, J. (2001). Closed Circuit Television. Elsevier Ltd. ISBN13:978-0-7506-8162-9. 2001

Cristian, C., Ursache, A., Popa, D. O., Florin, P. (2016). Energy Efficiently and Robustness for IoT: Building a Smart Home Security System. Faculty of Automatic Control and Computers. University Politehnica of Bucharest, Bucharest, Romania 43Govinda, K., Sai Krishna, P.,K, Sairam, S. (2014). Intrusion Detection System for Smart Home Using Laser Rays. International for Scientific Research and Development (IJSRD), 2, 176-78.

Dae-Yong, K. Young-Sik,J. Seokhoon, K. (2017). Data Filtering System to Avoid Total Data Distortion in IoT Networking. Symmetry. Doi: 10.3390/sym9010016.

Jayashri, B., Arvind, S. (2013). Design and Imlementation of Security for Smart Home Based on GSM Technology. Iternational Journal of Smart Home 7. 201-08.

Karri, V., Daniel Lim, J., S. (2005). Method and Device to communicate via SMS After a Security Intrusion. $1^{\text {st }}$ International Confrence on Sensing Technology. Palmerston North New Zealand, 21-23.

Lidyawati, L. Kristiana, L., Darlis, A. R., Jambola, L., Susana, R. (2020). Remotely Garden Irrigation for Residential Area Based on Internet of Things (IoT). Reka Elkomika: Jurnal Pengabdian kepada Masyarakat.

Sugiono, Indrayani, T., Ruswiansari,M. (2017). Kontrol jarak Jauh Sistem Irigasi Sawah Berbasis Internet of Things (IoT). INTEGER: Journal of Information Technology, Vol. 2, No. 2, 41-48, ISSN: 2579-566X

Sachin, K., Prayag, T., Mikhail, Z. (2019). Internet of Things is a Revolutionary Approach for Future Technology Enhancement: a Review. Journal of Big Data. 